\title{
Business Management Strategies for Business Development. Organization of the Territory and Planning of Construction Works
}

\author{
Nicolae Postavaru, Gabriela Draghici, Cosmin Filip, Al-Rubaye Mohammed, Sami Mahdi
} Mohammed

\begin{abstract}
In order for a project to be built with respect to quality, budget compliance and execution time - all required conditions, a professional management of site-level operations is required. The technical complexity, the importance of performing the work on the set deadline, the resource constraints and the substantial costs require the planning, programming and rigorous control of all the works.
\end{abstract}

Keywords - business sustainability, optimization, planning, spatial planning

\section{INTRODUCTION}

The process of building is a complex phenomenon, a mechanism without selfregulation. This process requires well-coordinated interventions of experts to ensure that activities are carried out according to the project requirements.

The realization of the construction can be profoundly affected by events that are sometimes difficult or even impossible to predict.

Under such changing circumstances, the costs and duration of activities can change constantly and may suddenly deteriorate. Exercising effective management, including rigorous planning of activities, is a must for achieving a satisfactory final result.

Regardless of the contractual arrangement chosen for building a construction project, the surest way to reach the objectives of all participants is to establish clear business development strategies. Corresponding to the chosen development strategies, a corresponding project management system will be implemented.

\section{DESCRIPTION OF THE THEORETICAL MODEL}

The theoretical model that we propose and which we will study is based on the method of comparison of significant parameters in the building process. The parameters we refer to are:

- choosing the constructive system,

- runtime,

- the cost per square meter resulted

These parameters resulted from the establishment of the business development strategy, from own sources. Starting from this point, the mission and vision of the business, 
the costs necessary for the implementation of the project and the time needed to obtain the first profit were established.

\section{RESULTS AND THEIR SIGNIFICANCE}

\subsection{Defining Managerial Strategy}

Alfred Chandler (1962) defines managerial strategy as "the long-term determination of the goals and objectives of an enterprise, the adoption of courses of action and the allocation of resources needed to achieve the objectives." The strategy provides an organization with opportunities to build and maintain a competitive edge, develop unique or performing success factors and competencies, use critical resources effectively, respond to environmental challenges quickly, outsource activities, and create partnerships to achieve efficiency, to obtain information about competitors and apply best practices in management, to create flexibility to respond successfully to market competition.

The "top" management develops an "intent" strategy, which is limited because it is the result of negotiation and compromise with the other structures. By adapting it to the environmental conditions and the way of implementation at the level of the inferior structures results "the realized strategy" which will represent only 10-30\% of the strategy of intent.

The two strategies belong to the two diametrically opposed schools: the design strategy school (Mintzberg) in which the strategy is built at the top and communicated to the inferior structures to be implemented and the Boston Consulting Group, where the strategy is being built "from went "based on the accumulated experiences.

The major arguments for the process strategy are: allows the organization to adapt to the rapid changes of the environment, generates a long-term targeting of the activity, confers advantages in competition in a high-risk environment, the organization becomes more efficient. (Grant R.M., Contemporary Strategy Analysis, Blackwell, 1998, p.19)

Any organization is guided by a strategy that includes at least the following elements: mission, vision, objectives and values, resources and capabilities, structures and systems, strategic options, policies, plan and action program that are in constant adaptation to the environment Business. (Doval E., Economic Forecast in Business Management, Ed. Of Tomorrow Romania Foundation, Bucharest, 2007)

Objectives represent future states that support the mission and vision of the firm and which create the elements of stability and the values of the organization. Objectives are often called "targets" and are "key elements of the theoretical plans, usually incorporated in annual plans" [G.A. Cole, 1994].

From the point of view of the sizes in which the objectives are expressed, two main forms will be distinguished:

- financial objectives, with predominance in monetary units,

- strategic objectives, with expression in physical or other units

It also distinguishes between the official, public and operational objectives that guide the company's activity. (Doval E. (2008) op cit., Pp. 44-45.)

From the point of view of the time factor, the objectives can be ranked as follows:

- strategic objectives - for strategic horizons of over 5 years;

- tactical objectives - for strategic horizons over 3 years;

- Operational objectives - for strategic horizons of over 1 year.

In managerial theory, goals are considered to meet the following set of conditions: measurability, acceptability, flexibility, clarity, realism, motivation. 


\subsection{Mechanisms of thinking in the strategic process}

Strategic management is a combination of processes that can have different approaches.

\subsubsection{The Lemon Consulting approach}

The Lemon Consulting approach (Lemon Consulting, www.lemon-consulting.com) includes:

- strategy formulation,

- strategy implementation,

- strategy evaluation.

Strategy formulation

This process consists of three steps: the analysis of the existing situation, the selfevaluation and the analysis of the micro and macro environment, including the analysis of the competitors.

The formulation of the strategy is a process that refers to answering 3 questions:

1) Where are we in this moment?

2) Where do we want to go?

3) How do we want to get there?

The answer to these questions determines the strategic plan.

\section{Strategy implementation}

This process includes: allocating and managing the necessary and sufficient resources (financial, personnel, time, technological support); establishing the control chain and the alternative structure (interconnected functional teams); assigning responsibilities to specific tasks or processes specific to individuals or groups; process management (this includes monitoring the results, comparing them with benchmarking and good practices, assessing the effectiveness and efficiency of the process, controlling variations and making adjustments if necessary).

\section{Strategy evaluation}

The evaluation of the strategy is to measure the effectiveness of the organization's strategy. This can be done through a SWOT analysis (Strengths, Weaknesses, Opportunities, Threats). It may be necessary to take precautions or even change the whole strategy.

\subsubsection{The approach of Johnson and Scholes}

The Johnson and Scholes approach (Johnson G., Scholes, K., Exploring corporate strategy, Forth edition, Prentice Hall, London, 1997) of the strategic process comprises three main steps: strategic analysis, strategic choice and strategy implementation.

Strategic analysis refers to the analysis of the environment in which the organization operates, and its analysis of the external environment, the context and the industry in which it operates.

Strategic choice harmonizes the environment with the organization's strategic goals and includes the steps: identifying options, evaluating options, analyzing stakeholder expectations, and selecting the strategy.

Implementation of the strategy includes: planning and allocating resources, implementing change in culture and organizational structure, and evaluating the strategy.

Whatever the model of approach to the strategic process, it must focus on the direction the organization is about to move, starting from the existing situation (internal and external) so as to ensure its success. 


\section{sciendo}

48 Ovidius University Annals Series: Civil Engineering, Year 21, 2019

\subsubsection{Presentation of concepts on planning of construction works and activity planning}

The planning of the building-assembly works is aimed at achieving a more economical layout of their execution. This is reflected in a program (calendar and / or network) included in the site organization project.

Scheduled works can be done through classical, intuitive methods applied from ancient times without realizing that this need will generate the development of a science or currently various programs that underlie automated computation

Classical methods are based on calendar planning and scheduling.

The elaboration of the calendar is made taking into account the specifications in the technological sheets, in the following stages:

- Dividing complex work processes into simple processes and determining the volumes of their works;

- Establishing the best technological succession to eliminate the non-synchronization and ensure the execution of works in parallel;

- Coordination of the deadlines for each work process to fit the proposed execution time.

Domain Literature (Cagle, Ronald B. Blueprint for Project Recovery: A Project Management Guide: New York: AMACOM, 2002) recalls the appearance in 1957 of "CPM-Critical Path Method ", developed and used in the US to improve the calendar plans for construction and assembly works in the chemical industry. Further, in 1958, "P.E.R.T. Program Evaluation and Review Technique" was elaborated.

From these two main methods based on network graph theory, other methods have been derived. In all methods, the execution time, the resource level, and the total cost are tracked.

The main elements of a graph are:

- activity,

- phase,

- the path.

It can be considered activity: a simple working process (excavation, concrete casting, masonry, etc.) that consumes time and resources for its realization; a natural process (paint drying, concrete reinforcement, etc.); a wait, which consumes time but does not consume resources; a technological conditioning or an organizational (fictive activity) that does not consume any time or resources, but makes it necessary to start the next activities by completing its previous activities.

The phase or event represents a certain stage of the work and defines the beginning and the end of one or more activities without consuming time and resources. In a network graph, there is only one initial and final phase and one or more intermediate phases.

The path, in a network graph, is a sequence of activities and phases between the initial phase and the final phase of the network. The length of the road actually refers to its length and is calculated by summing up the duration of the activities that make up that road.

The critical path, in a network graph, is the longest route, obtained as the sum of the duration of the activities between the initial phase and the final phase.

Critical duration is the minimum length of time that the entire complex process can be executed, because it includes the division of activities with the longest duration (critical activities). Since overtaking the duration of a single critical activity leads to an increase in the duration of the entire work, the production management staff must pay particular attention to these activities. 


\subsection{Analysis of the proposed model and its significance}

The proposed model refers to the development of the business by building a resort house that will create a profit in the future. In order to efficiently organize the owneroccupied territory, the owner assessed the two schools of thought described in point 3.2. and opted for the Lemon Consulting approach.

To go through all the stages of the Lemon Consulting algorithm, the owner who also held the project manager role systematically planned the scheduling of work and estimating the required budget.

The case study, analyzed, presents the choice of an optimal construction solution for a 4500 square meter plot that will serve as a resort, in a mountainous area, where there is thermal water.

Entry data refers to a capacity of 24 rooms, each of which has its own toilet, a restaurant with a capacity of 100 seats and a pool with thermal water, uncovered, equipped with a sas from the guesthouse to the pool, total area 300 square meters. Also, at least 28 parking spaces must be provided which do not affect the aesthetics of the built-in assembly.

The first option consisted in designing a ground floor and three-storey hotel to provide the necessary room. The resistance structure was in monolith reinforced concrete frames on reinforced concrete beams found under the pillars.

The structure was dimensioned, the workloads were calculated, the execution technology was designed and resulted in a cost price of 450 euro / square meter built.

The architecture respects the mountain specificity, namely the use of a four-sloped roof structure.

Costs for foundation, superstructure, and facilities, including equipment endowment and finishing costs have been differentiated.

Activities were also planned using the CPM and resulted in a seven-month execution time without human or law interruptions, and without taking account of weather conditions. For this reason, a three-month reserve has been added to the seven-month period for the various interruptions that may occur so that the maximum duration was ten months.

This constructive system resulted in a cost of 450 euro $/ \mathrm{m}^{2}$, due to the more complex installation system in the case of a double-decked building.

The second variant consisted in the design of four ground-floor structures, of loadbearing masonry, with lower and upper belts and concrete pillars, equivalent to the structure made in the first variant and providing the same number of rooms.

Running the same calculations resulted in: a runtime similar to the first option (approximately 7 months) because there are works that can be executed in parallel, without significantly increasing the number of teams and a cost of 300 euro $/ \mathrm{m}^{2}$.

\section{CONCLUSION}

It is noted that, based on the results obtained, according to the stated theories and the practice presented in the Project Management Institute (PMBOK Guide), the 6th edition of the Project Management Institute 2017), the following objectives can be set:

- efficient organization of the territory in order to obtain a maximum profit in terms of the environment protection and the optimal classification of the constructions in the environment

- establishing the optimal budget for project implementation 


\section{sciendo}

50 Ovidius University Annals Series: Civil Engineering, Year 21, 2019

- staggering the budget according to the necessity and the opportunity to finance the phased work so that the money is spent with responsibility

- determining the duration of execution

- establishment of the workers' teams needed at various stages of construction

It can be said that by extrapolating from the strategic and project management applied to the project in question to the day-to-day facts, the strategic management correlated with the project management develops the skills to think logically, to plan our actions which we want to do and plan the money we want or can afford to spend.

\section{REFERENCES}

[1] Cagle, Ronald B. Blueprint for Project Recovery: A Project Management Guide: The Complete Process for Getting Derailed Projects Back on the Track. New York: Amacom, 2002

[2] Chandler, A.D., Strategy and Structure, M.I.T. Press, 1962

[3] Doval E., Previziunea Economică în Managementul Firmei, Ed. Fundaţiei România De Mâine, Bucureşti, 2007

[4] Doval E., Analiza Strategică a Mediului Concurenţial, Editura Fundaţiei România De Mâine, Bucureşti, 2008

[5] Grant R.M., Contemporary Strategy Analysis, Blackwell, 1998, p.19

[6] Johnson G., Scholes, K., Exploring Corporate Strategy, Forth Edition, Prentice Hall, London, 1997

[7] Lemon Consulting, www.lemon-consulting.com

[8] Project Management Institute. A Guide to the Project Management Body of Knowledge (Pmbok Guide) - Project Management Institute - Editia A 6-A, 2017

[9] Strategy, Curs MBA, Vol. 1-10, The Open University Business School, Uk, 1998

Note:

Nicolae Postavaru- Technical University of Civil Engineering Bucharest, Romania (e-mail: nicolae.postavaru@gmail.com)

Gabriela Draghici- Ovidius University of Constanta, Constanta, România (e-mail: g.draghici@yahoo.com)

Cosmin Filip- Ovidius University of Constanta, Constanta, România (e-mail: filip.cosmin@yahoo.com)

Mohammed Al-Rubaye - PH.D. Student - Technical University of Civil Engineering Bucharest, Romania

Mohammed Sami Mahdi - PH.D. Student - Technical University of Civil Engineering Bucharest,

Romania 